\title{
Keindahan seni manik etnik Lun Bawang di Lawas, Sarawak
}

\author{
The beauty of the Lun Bawang beads society in Lawas, Sarawak \\ Mohamad NurHanif Hazman*, Harozila Ramli \& Tajul Shuhaizam Said \\ Fakulti Seni, Komputeran \& Industri Kreatif, \\ Universiti Pendidikan Sultan Idris, Tanjong Malim, Perak, Malaysia \\ *e-mail: hanifmmkhar1617@gmail.com
}

Published: 29 May 2020

To cite this article (APA): Hazman, M. N., Ramli, H., \& Said, T. S. (2020). Keindahan seni manik etnik Lun Bawang di Lawas, Sarawak. EDUCATUM Journal of Social Sciences,6(1), 43-52. https://doi.org/10.37134/ejoss.vol6.1.5.2020

To link to this article: https://doi.org/10.37134/ejoss.vol6.1.5.2020

\begin{abstract}
Abstrak
Kajian ini memfokuskan kepada keindahan seni manik etnik Lun Bawang di Lawas, Sarawak menerusi penghasilan kraf manik seramik dari segi olahan, penggunaan bahan, mereka corak dan proses penghasilannya. Cetusan idea kajian ini terhasil bertujuan untuk mengangkat seni manik etnik Lun Bawang ini ke peringkat lebih tinggi dan memberi pendedahan kepada etnik untuk memperlihatkan kearifan lokal etnik ini mampu mempengaruhi kreativiti seni manik di Sarawak. Keunikan kraf manik etnik Lun Bawang ini sebenarnya terletak pada reka corak motifnya yang digunakan, bahan serta cara penghasilannya. Motif-motif tradisional etnik ini digambarkan dan diinterpretasikan pada permukaan manik berfungsi untuk mencerminkan identiti dan kebudayaan etnik Lun Bawang dan memberi simbolik estetika yang tinggi serta keindahan pada manik tersebut. Kaedah kualitatif menerusi pendekatan historikal telah membuktikan bahawa masyarakat setempat bijak mengadaptasikan sumber alam dan identiti etnik mereka dalam penghasilan seni manik ini. Nilai keindahan apreasasi etnik Lun Bawang ini terhadap penghasilan seni manik dalam budaya mereka adalah satu refeleksi kearifan lokal terhadap ketelitian observasi tentang fungsi dan sifat bahan alam sebagai bahan utama bagi penghasilan objek seni terutama manik.
\end{abstract}

Kata kunci: keindahan, kearifan lokal, Lun Bawang, manik

\begin{abstract}
This study focuses on the beauty of Lun Bawang ethnic beads in Lawas, Sarawak through the manufacture of ceramic bead crafts in terms of processing, material use, design and production process. The idea of this study was aimed at elevating Lun Bawang's bead art to a higher level and exposing the ethnic group to show that local ethnic wisdom could influence the creativity of the bead art in Sarawak. The uniqueness of Lun Bawang's ethnic bead crafts is actually based on the design of the motif used, its materials and its means of production. These traditional ethnic motifs depicted and interpreted on the bead surface serve to reflect the Lun Bawang ethnic identity and culture and provide a high aesthetic symbolism and beauty to the bead. Qualitative methods through historical approaches have proven that local people are wise to adapt their natural source and ethnic identity to the production of these bead art. The value of Lun Bawang's ethnic aesthetic appeal to the production of bead art in their culture is a reflection of local wisdom on the observational study of the function and nature of natural materials as a key ingredient for the production of art objects especially beads.
\end{abstract}

Keyword: beuty, local culture, Lun Bawang, beads 


\section{PENGENALAN}

Etnik Lun Bawang yang mendiami kawasan di daerah Lawas, Sarawak kaya dengan kraf tradisional yang telah dipraktiskan sejak zaman dahulu lagi. Kraf manik tradisional Lun Bawang mempunyai nilai estetika yang tinggi dalam etniknya. Bagi kaum Lun Bawang, kraf manik nilainya begitu tinggi sehingga dapat menyaingi barang kemas yang dipakai oleh wanita pada hari ini. Etnik Lun Bawang menggunakan manik ini sebagai satu hiasan peribadi yang dipakai dalam kehidupan seharian mereka. Mereka mengangkat bahawa kraf manik ini sebagai satu warisan nenek moyang mereka yang perlu diteruskan kerana ia sudah berzaman lagi digunakan di samping penghasilan seni manik ini merupakan buatan mereka sendiri mengikut cita rasa, fesyen dan mengaplikasikan motif-motif tradisi suku kaum mereka. Sesetengah etnik Lun Bawang ini telah mula menghasilkan semula manik legap yang dikatakan salah satu manik kegemaran mereka di mana manik ini dihasilkan dengan menggunakan tanah liat yang diambil sumbernya dari Sungai Lawas. Manik tanah liat ini dijual dan dipakai semasa majlis-majlis rasmi dan juga semasa perkahwinan. Kini, industri kraf manik seramik buatan tangan dihasilkan dengan menggunakan reka bentuk dan reka letak yang baharu di mana bersesuaian dengan peredaran masa pada hari ini namun masih lagi mengekalkan motif dan identiti etnik Lun Bawang ini. Seiring dengan kemajuan teknologi, kraf manik seramik Lun Bawang ini telah mengaplikasikan dan mengadaptasi penggunaan peralatan moden yang dapat meningkatkan jumlah pengeluaran manik Lun Bawang dari masa ke masa di samping menitik beratkan kualiti seni manik yang dihasilkan. Kelangsungan penghasilan seni manik Lun Bawang ini diharapkan dapat diteruskan dengan menambah nilai estetika yang tinggi serta memberi nilai keindahan yang tinggi terhadap seni manik yang dihasilkan oleh etnik Lun Bawang ini.

\section{ASAL USUL ETNIK LUN BAWANG}

Lun Bawang ini sebenarnya membawa kepada maksud orang di kawasan pedalaman ( people of the interior ). "Lun" bermaksud orang manakala "Bawang" membawa maksud ulu. Secara keseluruhannya, Lun Bawang bererti orang ulu. Pada asalnya, Lun Bawang ini merujuk kepada etnik Murut kerana kedua-dua etnik ini hampir sama dari beberapa aspek. Terdapat beberapa jenis etnik yang sinonim dengan Lun Bawang iaitu Lun Dayeh etnik Lun Bawang yang dikenali di Sabah, Lun Lod yakni etnik Lun Bawang ada di sekitar kawasan hilir sungai (downriver). Etnik Lun Bawang boleh ditemui di sekitar bahagian Lawas, Limbang; Trusan; Kalimantan, Indonesia; dan Temburong, Brunei yakni di tengah kawasan pedalaman Borneo. Lawas merupakan pekan kecil yang terletak bersebelahan dengan negeri Sabah.

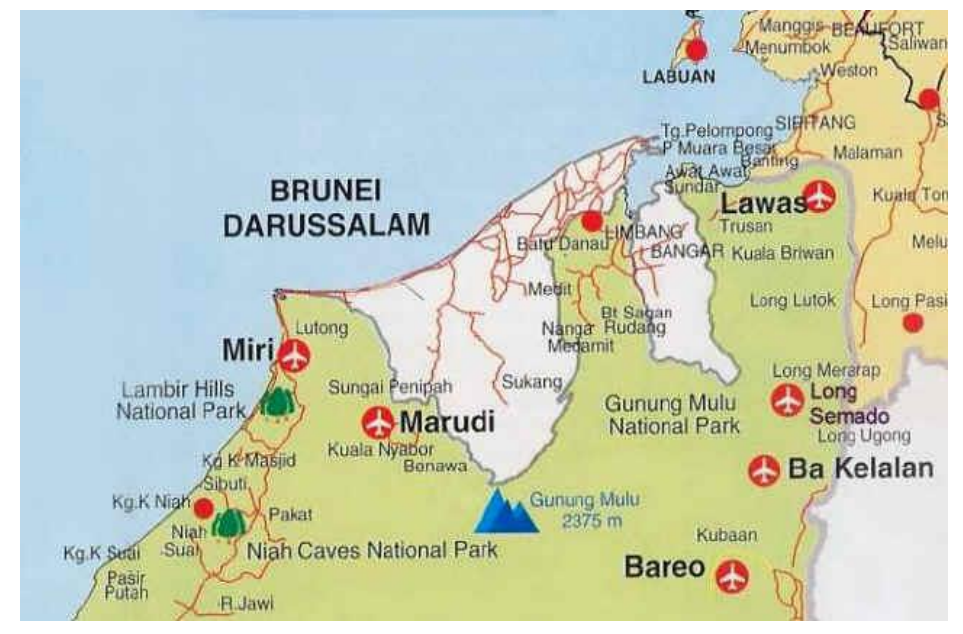

Gambar 1: Peta Daerah Lawas, Sarawak.

Sumber: http://sam4605.blogspot.com/2009/10/mission-4-kk-papar-keningau-tenom-lawas.html 
Kebanyakan etnik Lun Bawang telah berhijrah ke bandar-bandar besar seperti di Kuching, Miri dan Sibu kerana mereka bekerja di sana. Selain itu, ada juga sebilangan etnik Lun Bawang berhijrah ke Brunei dan negeri Sabah untuk mencari rezeki di sana. Dikatakan kawasan yang mula-mula didiami oleh etnik ini adalah di kawasan Hulu Trusan dan Sungai Kelalan sejak berkurun lamanya. Etnik yang mendiami kawasan tersebut adalah berketurunan Labu Danur sehingga terdapat sebuah sungai yang telah mendapat nama Sungai Labu atau Abpa Labu. Etnik Lun Bawang menamakan diri mereka sebagai etnik Lun Dayeh bagi mereka menetap di kawasan hulu sungai termasuk di kawasan pergunungan dan faktor gelaran ini bukanlah untuk membezakan kaum Lun Bawang tetapi disebabkan faktor geografi yang mana perbezaan kawasan yang didiami sahaja. Ternyata, gelaran ini memberikan kesan yang baik di mana seseorang kaum Lun Bawang dapat mengenali sejarah atau latar belakang diri berdasarkan kawasan yang mereka diami.

Etnik Lun Bawang ini sangat terkenal dan popular di Sarawak melalui rekaan dan keunikan maniknya. Manik etnik Lun Bawang ini merupakan sumbangan besar kepada industri manik di Sarawak. Manik ini sebenarnya merupakan satu seni kraf tangan yang sangat popular di Sarawak. Sejak zaman berzaman kemahiran mengubah manik telah menjadi satu seni tradisi dalam kalangan etnik etnik Sabah dan Sarawak. Keistimewaan manik etnik ini dapat dilihat melalui olahan rekaan motif setiap manik yang dihasilkan. Setiap reka corak manik yang direka oleh etnik ini memiliki nama yang tersendiri sebagai contoh corak chevron, corak bengkang bengkok, corak potongan wajik dan sebagainya. Senario pemilihan motif dan reka corak seni manik Lun Bawang ini banyak dipengaruhi oleh faktor persekitaran dan tumbuhan yang berada di sekeliling mereka.

Penerokaan terhadap bahan-bahan dan proses penghasilan manik ini juga merujuk kepada kearifan lokal etnik ini dalam mengekalkan beberapa identiti etnik mereka agar seni manik Lun Bawang ini tidak sama sekali dengan seni manik etnik lain yang turut membangunkan seni kraf tangan ini di Sarawak. Tidak dapat dinafikan lagi, pengaruh seni manik etnik Lun Bawang ini begitu besar kepada industri manik di Sarawak kerana ia merupakan salah satu seni manik yang sangat popular di sana setaraf dengan seni manik etnik lain yang terdapat di Sarawak. Oleh hal yang demikian, kajian ini dilakukan bagi melihat bagaimana seni manik etnik Lun Bawang ini mampu mengangkat kearifan mereka dalam meningkatkan kreativiti dalam penghasilan seni manik di Sarawak.

\section{FENOMENA SENI MANIK LUN BAWANG}

Penghasilan seni manik etnik Lun Bawang ini merupakan salah satu fenomena yang terbesar di dalam industri seni manik di Sarawak. Manik Lun Bawang ini merupakan salah satu penyumbang terbesar di dalam industri seni manik di Sarawak selain etnik lain seperti Murut, Dusun dan sebagainya. Keindahan seni manik Lun Bawang ini tidak dapat dinafikan lagi kerana setiap perincian dan penghasilan seni manik ini tidak sama sekali dengan seni manik yang dihasilkan oleh kaum lain. Manik Lun Bawang ini dikatakan mempunyai identiti tersendiri selari dengan refleksi daripada kearifan lokal mereka dalam penghasilan manik ini. Di dalam kajian ini, keindahan seni manik Lun Bawang ini telah dibahagikan kepada beberapa bahagian antaranya ialah dari segi penggunaan bahan tanah liat, reka corak motif dan proses penghasilannya.

Sememangnya manik seramik yang dihasilkan oleh Lun bawang ini asalnya daripada tanah liat yang melalui proses pembakaran. Tanah liat ini diambil dari sungai di kawasan Lawas, Sarawak kerana tanah liat ini merupakan tanah jenis Tanah Alluvial atau Tanah Endapan. Tanah Alluvial ialah sejenis tanah yang umumnya terdapat di sepanjang aliran sungai. Sifat tanah ini sangat dipengaruhi oleh material yang terkandung dalam sungai yang melaluinya. Tanah alluvial atau alluvium ini adalah tanah hasil pengikisan tebingan sungai yang diendap di dataran rendah. Ciri-ciri tanah alluvial ini adalah berwarna kelabu dan subur. Tanah ini sesuai untuk tanaman padi, tebu, kelapa, tembakau, dan buah-buahan. Oleh itu, etnik Lun Bawang ini menjadikan tanah daripada sungai Lawas ini sebagai sumber utama untuk menghasilkan manik mereka.

Dalam dapatan kajian ini juga motif merupakan tunjang utama dalam penghasilan kraf-kraf tradisional. Motif ini menjadi dasar kepada penghasilan kraf manik di mana setiap manik yang dihasilkan diletakkan motif-motif yang menjadi ikon atau lambang sesebuah etnik itu. Begitu juga etnik Lun Bawang yang sememangnya menjadikan motif dan identiti Lun Bawang sebagai lambang pada hasil seni manik yang 
dihasilkan. Motif yang digunakan oleh Lun Bawang ini kebanyakan dipengaruhi oleh sumber alam seperti flora dan fauna. Bagi Lun Bawang istilah motif dikenali sebagai "arit" yang membawa maksud motif. Hasil kajian ini mendapati beberapa jenis motif yang dihasilkan oleh etnik Lun Bawang di dalam penghasilan seni maniknya mempunyai nilai estetika dan keindahannya yang tersendiri.

\section{MOTIF MANIK}

Pecahan motif manik Lun Bawang ini terbahagi kepada beberapa kategori antaranya ialah motif berasaskan tumbuh-tumbuhan iaitu yang diadaptasi daripada pokok buluh kerana pokok buluh ini banyak ditemui di kawasan ini. Hasil dapatan mendapati bahawa antara motif yang berasaskan buluh ialah Motif Bamboo (Arit Bulu), Motif Bamboo bertemu (Arit Bulu Nepapu) dan juga Motif Rebuyung (Rebuyung Arit Bulu).

a. Motif Bamboo (Arit Bulu)

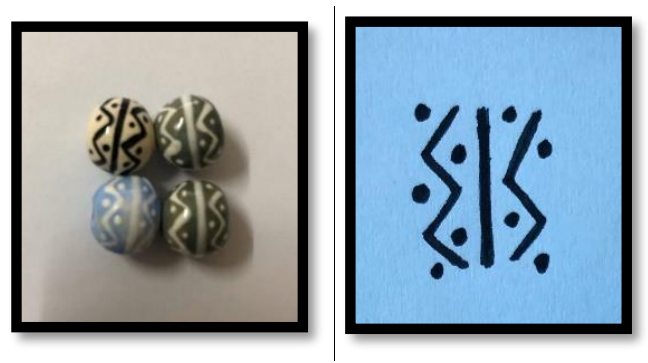

b. Motif Bamboo Bertemu (Arit Bulu Nepapu)

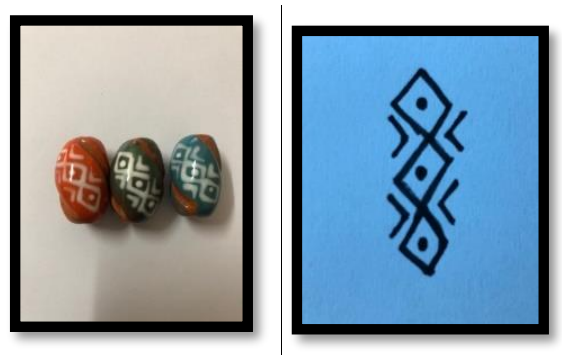

c. Motif Rebuyung (Rebuyung Arit Bulu)

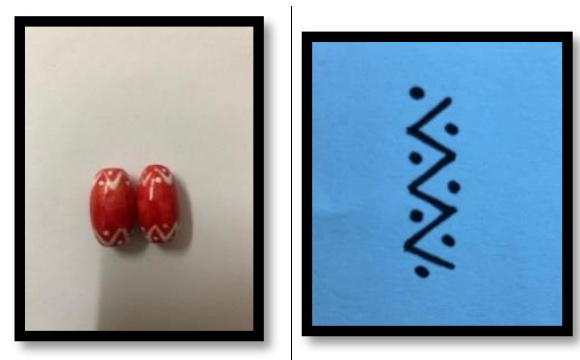

Manakala, Lun Bawang juga memperkenalkan motif-motif manik mereka yang berunsurkan haiwan. Motif yang berunsurkan haiwan ini antaranya diadaptasi daripada motif burung tiung iaitu Motif Mata Burung Tiung (Arit Mateh Siuk) kerana di Sarawak burung ini sangat popular dan banyak ditemui di kawasan Lawas dan juga motif harimau iaitu Motif Mata Harimau (Arit Mata Balang) dan juga ramarama iaitu Motif Rama-Rama (Arit Belepang) merupakan motif yang sangat popular bagi etnik Lun Bawang ini. Kedua-dua motif ini banyak dijumpai pada manik di mana kebiasaannya ia di jadikan gelang atau rantai. Dan juga terdapat motif yang berunsurkan daripada tulang haiwan iaitu Motif Bau Tulang (Bau Tulang Arit Bulu). 
a. Motif Mata Burung Tiung (Arit Mateh Siuk)
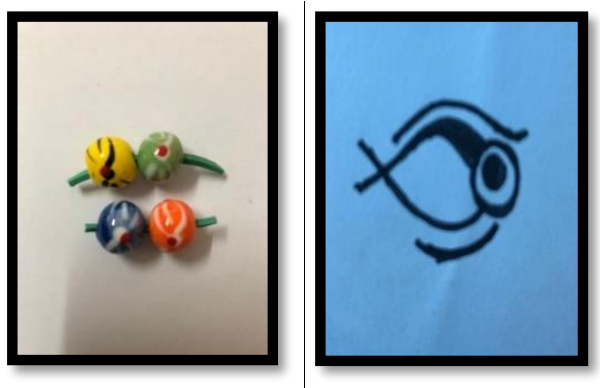

b. Motif Bau Tulang ( Bau Tulang Arit Bulu)

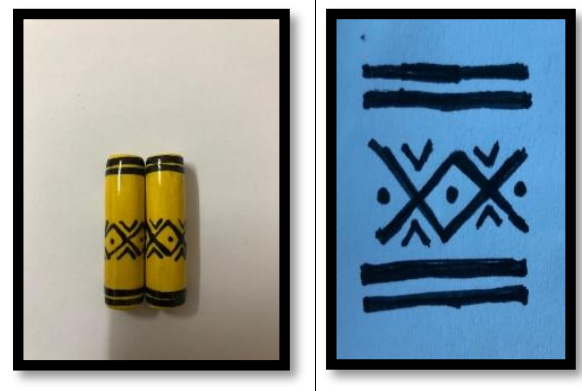

c. Motif Rama-Rama (Arit Belepang)
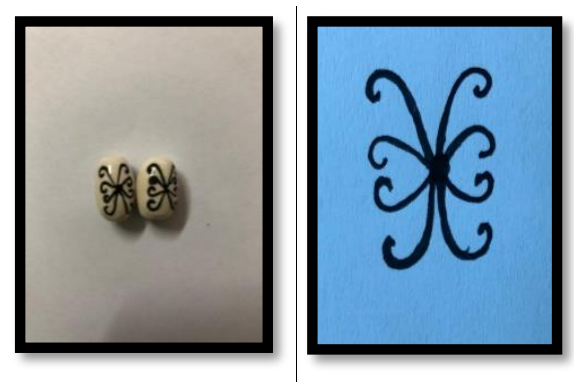

d. Motif Mata Harimau (Arit Mateh Balang)
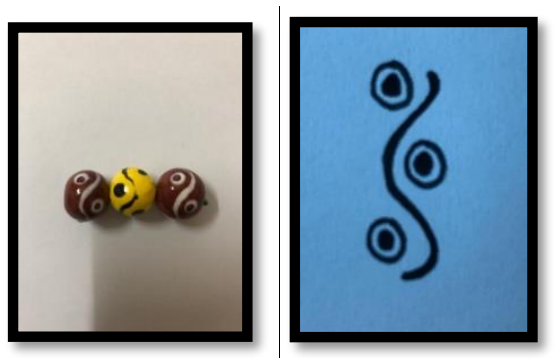

Selain itu juga, Lun Bawang juga menggunakan motif-motif yang berunsurkan simbol abjad seperti simbol S iaitu Motif Bentuk S Yang Disambung (Arit Sarawak) dan juga terdapat motif yang menggunakan bentuk seperti bentuk hati iaitu Motif Bentuk Love (Arit Love). Lun Bawang kebanyakan memvariasikan kepelbagaian motif agar manik yang dihasilkan unik dan menarik sebagai simbolik identiti mereka. Seterusnya, motif paling ketara menggambarkan identiti Lun Bawang ini adalah simbolik motif daripada topi mereka iaitu topi rong iaitu Motif Topi Rong (Arit Rong). Motif ini kebiasaannya dijumpai pada rantai dan juga gelang manik Lun Bawang. 
a. Bentuk S Yang Disambung (Arit Sarawak)
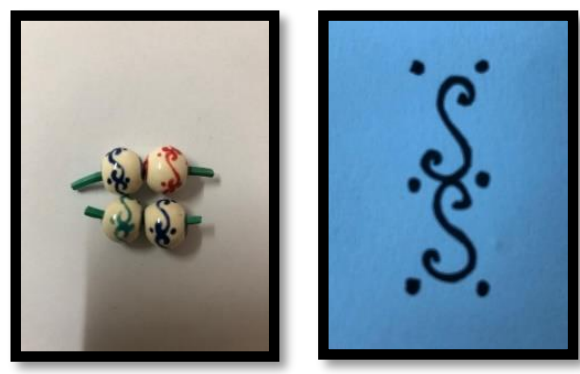

b. Motif Topi Rong (Arit Rong)
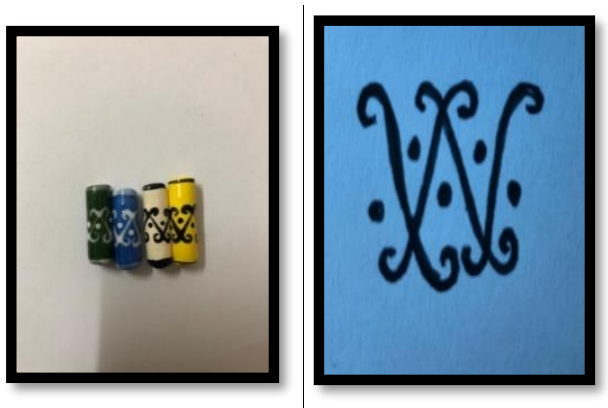

\section{c. Motif Bentuk Love (Arit Love)}
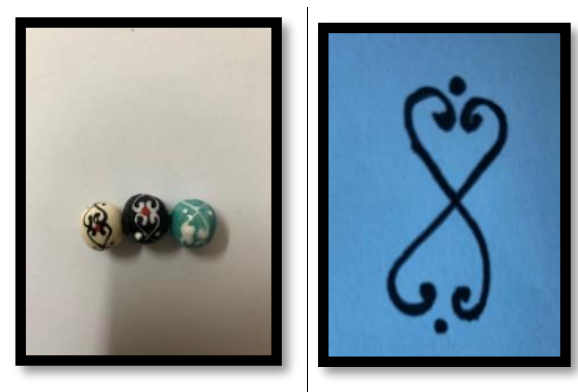

\section{BENTUK DAN SAIZ MANIK}

Keindahan seni manik lun bawang ini juga dpat dilihat menerusi bentuk dan saiz maniknya. Saiz dan bentuk manik setiap kaum adalah tidak sama begitu juga dengan seni manik Lun Bawang ini. Kebanyakan saiz dan bentuk maniknya berbeza mengikut motif-motif yang dihasilkan. Terdapat pelbagai saiz dan terdapat di dalam seni manik Lun Bawang ini dan antaranya ialah:

\section{a. Bentuk Memanjang}

Bentuk memanjang ini terdapat dua jenis saiz terdapat bentuk memanjang besar dan saiz yang kecil. Bagi bentuk memanjang besar kebiasaannya saiznya berukuran $3.5 \mathrm{~cm}$ manakala saiz manik memanjang kecil pula berukuran $2 \mathrm{~cm}$. Dan saiz manik ini kebiasaannya digunakan untuk menghasilkan rantai dan tali pinggang. 


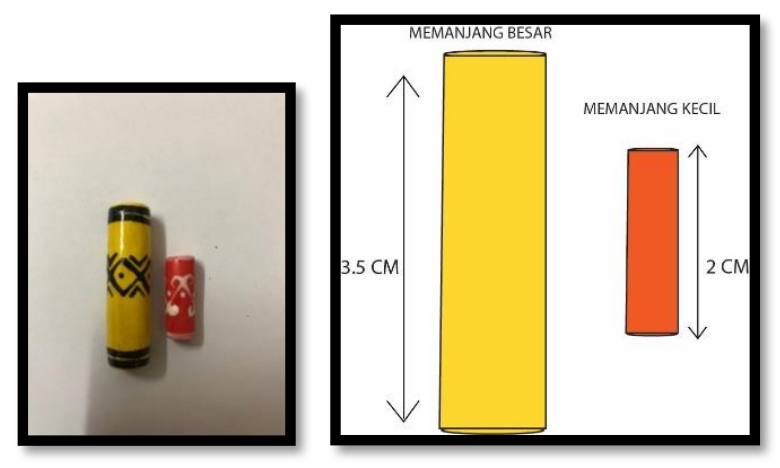

\section{b. Bentuk Bulat}

Manik Lun Bawang ini terdapat juga bentuk bulat. Seni manik Lun Bawang jenis bulat ini terdapat dua jenis iaitu bulat besar yang berukuran $1.2 \mathrm{~cm}$ dengan diameter $1 \mathrm{~cm}$ dan juga bulat kecil yang berukuran $1 \mathrm{~cm}$ dengan diameter $0.5 \mathrm{~cm}$. Manik jenis ini kebiasaan digunakan untuk menghasilkan gelang tangan dan juga topi di kepala bagi kaum wanita.
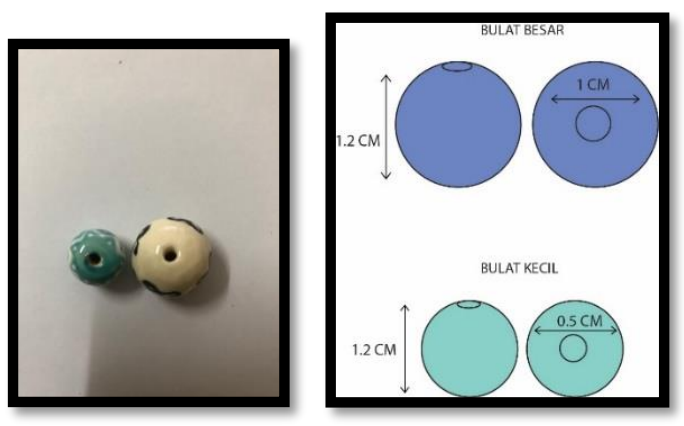

\section{c. Bentuk Bujur}

Manik Lun Bawang juga terdapat dalam bentuk bujur. Saiz manik ini berukuran $2 \mathrm{~cm}$ dan diameternya berukuran $0.5 \mathrm{~cm}$. Bentuk bujur ini kebiasaan digunakan untuk penghasilan rantai bagi kaum wanita.
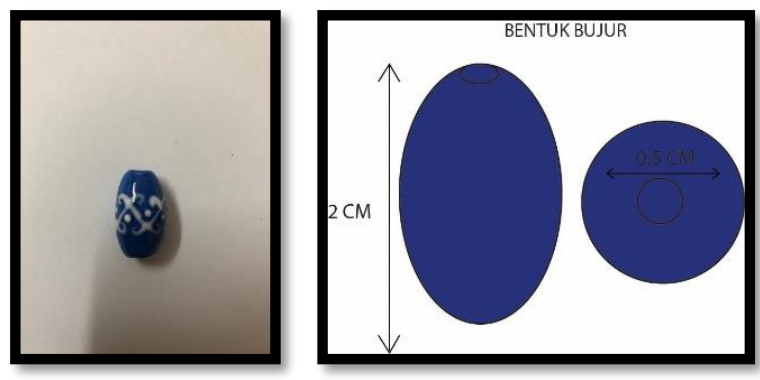

\section{d. Bentuk Bujur Berlekuk}

Manik ini juga terdapat dalam bentuk bujur namun berlekuk. Saiz manik berbentuk bujur berlekuk ini kebiasaannya berukuran $2.5 \mathrm{~cm}$ dengan diameter maniknya $0.5 \mathrm{~cm}$. Kebiasaannya corak ini dihasilkan mengikut motif yang digunakan. Saiz dan bentuk ini kebiasaannya digunakan untuk membuat rantai dan gelang tangan. 


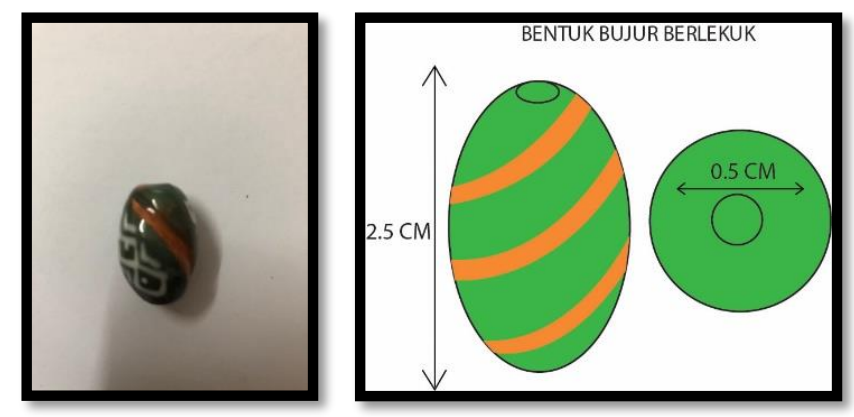

\section{PROSES PENGHASILAN}

Selain itu juga, warna merupakan salah satu faktor penting dalam penghasilan manik Lun Bawang ini. Kebanyakan warna yang dipilih oleh Lun Bawang ini diadaptasi daripada sumber alam. Oleh itu, antara warna yang sering digunakan adalah warna kuning, jingga, merah, biru, hijau, hitam, putih dan biru gelap. Warna-warna ini sememangnya sudah menjadi perlambangan bagi etnik Lun Bawang ini kerana sesetengah etnik dapat membezakan seni manik etnik Lun Bawang ini dengan etnik lain melalui penggunaan warna yang digunakan oleh mereka. Secara tradisional dan mengikut turun-temurun warna identiti etnik ini adalah warna kuning, merah, putih dan juga hitam yang terdapat pada topi atau pengikat kepala mereka yang dipanggil "pata bawa".

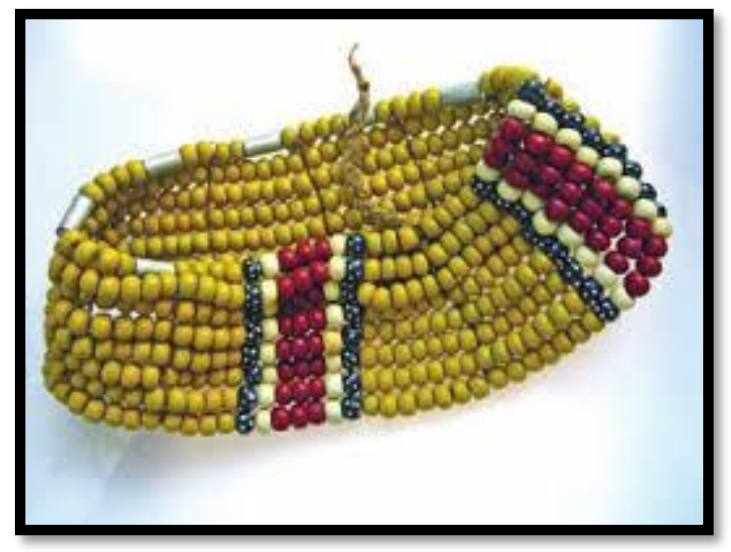

Gambar 1: Gambar Pata Baw. Sumber: Koleksi Pengkaji

Proses penghasilan manik Lun Bawang ini melalui beberapa proses iaitu proses pembakaran Bisque, proses Glaze dan juga pembakaran menggunakan teknik raku. Proses pembakaran bisque ini merupakan pembakaran suhu rendah di mana ia merupakan proses mengubah manik yang separa kering, menjadi manik yang padat, keras dan juga kuat. Pembakaran suhu rendah melibatkan suhu 900 darjah celsius selama 8 jam sehingga 9 jam. Pembakaran bisque ini merupakan tahap yang sangat penting kerana menjadikan manik separa kering kepada bisque dan istilah bisque ini merujuk kepada seramik yang telah dibakar pada kitaran suhu 700 hingga 1000 darjah celsius.

Pembakaran ini membuatkan manik Lun Bawang ini kuat, keras dan kedap air. Teknik glaze pada manik Lun Bawang ini berfungsi sebagai warna bertujuan untuk diwarnakan pada manik yang telah melalui pembakaran bisque. Proses glazing ini merupakan tahap yang menentukan ketimbulan corak dan warna pada manik sebelum proses pembakaran glazing. Manik yang telah melalui proses bisque dilapis dengan warna glazing melalui teknik celupan dan dicorakkan dengan menggunakan lidi atau berus warna yang kecil. Fungsi glazing ini adalah untuk menambah keindahan dari segi persembahan idea reka corak pada permukaan manik Lun Bawang ini. Manik yang telah disaluti glaze ini akan disusun pada stainless steel kerana untuk menampung suhu pembakaran manik akhir pada paras suhu 1100 hingga 1250 darjah 
celcius. Teknik raku ini merupakan teknik pembuatan glaze seramik yang menghasilkan kesan dan keunikan pada manik seramik disebabkan pengaruh pembakaran reduksi dalam sebuah bekas di mana ada sesetengah bekas diisi dengan habuk kayu, daun-daun kering dan sebagainya untuk menghasilkan kesan unik pada manik yang telah disapu glaze. Keunikan proses inilah menjadikan manik Lun Bawang ini sangat unik dan menjadi fenomena yang besar pengaruhnya di Lawas, Sarawak.

\section{KESIMPULAN}

Etnik Lun bawang ini merupakan salah sebuah kaum yang begitu menjaga warisan budaya nenek moyang mereka dan seni kraf tangan mereka hingga ke hari ini. Setiap identiti etnik Lun Bawang ini dapat diterokai dan difahami melalui hasil-hasil kraf tangan mereka seperti anyaman bakul, tikar, topi dan termasuklah perhiasan manik mereka ini. Idea dan konsep penghasilan seni manik Lun Bawang ini masih mengekalkan reka corak tradisi dan mengekalkan identiti etnik mereka yang dipelajari dari nenek moyang mereka. Sebagaimana yang kita tahu, warisan nenek moyang yang mereka kekalkan sehingga ke hari ini adalah penghasilan seni manik ini. Namun begitu, proses penghasilan manik pada masa dulu dan kini banyak mengalami perubahan dari segi kemudahan dan pewarnaan manik serta proses penghasilannya berdasarkan kearifan lokal mereka seiring dengan perkembangan peredaran masa. Kearifan lokal mereka ini serba sedikit dapat meningkatkan kreativiti dalam penghasilan seni manik Lun Bawang ini. Tradisi Lun Bawang dan manik-maniknya diyakini dapat menembusi pasaran luar sekali gus dapat meningkat dan memperkembangkan lagi industri seni manik di Sarawak serta mereka dapat mengekalkan tradisi ini sehingga generasi pada masa akan datang. Harapan agar etnik Lun Bawang ini terus memperkembangkan lagi seni manik mereka ini kepada etnik setempat agar seni manik mereka ini tidak luput ditelan arus peredaran masa dan terus dikenali oleh generasi akan datang.

\section{PENGHARGAAN}

Kajian ini tidak akan dapat disiapkan tanpa sumbangan dan sokongan daripada semua pihak terutamanya daripada pensyarah penyelia iaitu Prof Madya Dr. Harozila Binti Ramli dan Prof Tajul Shuhaizam Bin Said yang banyak membantu dan memberi bimbingan dalam menyiapkan kajian ini serta Pihak Institut Pengajian Siswazah Universiti Pendidikan Sultan Idris kerana ini merupakan salah satu syarat bergraduat bagi pelajar sarjana dalam bidang Pengajian Kraf.

\section{RUJUKAN}

Bell Su'ut. (2014). Estetika "Bakad” etnik Lun Bawang Lawas, Sarawak: Satu kelansungan pendidikan informal. Tanjung Malim: Universiti Pendidikan Sultan Idris.

Harozila Ramli, Tajul Shuhaizam, Mohamad NurHanif Hazman.2019. The Beauty of Tritik Technique in Creating Batik-textile Pattern Designs. Jornoul Of Advanced Research In Dynamical And Control System(JARDCS). Vol. 11, 05-Special Issue.

Harozila Ramli, Tajul Shuhaizam, Mohamad Zaihidee Arshad.2019. Symbolism of 'Keleput' Art and Intellectual Value of Penan Heritage Craft in Sarawak. Jornoul Of Advanced Research In Dynamical And Control System(JARDCS). Vol. 11, 05-Special Issue.

Harozila Ramli, Tajul Shuhaizam, Salwa Jamaldin, Mohamad NurHanif Hazman.2019. The Impact Of A Learning Module Based On Adobe Photoshop On The Teaching And Learning Of Batik Pattern. International Journal Of Innovation, Creativity And Change. Vol.6 Isssue 2.

Ibrahim Abu Shah. (1991). Industri Kecil Dan Sederhana Sarawak. Perpustakaan Negara Malaysia. Kuala Lumpur: Dewan Bahas Dan Pustaka.

Koleksi Manik Lun Bawang. Diperoleh pada 10Oktober 2019 daripada: http://nicitoden.blogspot.com/2013/12/koleksi-manik-puak-lun-bawang.html

Mohamad Yusof Kasim. (2002). Sabah Dan Sarawak Dalam Arus Globalisasi. Bangi: Universiti Kebangsaan Malaysia.

Meechang Tuie. (1995). Etnik Lun Bawang Sarawak suatu pengenalan. Kuching: Desktop Publishing Sdn.Bhd. 
Pengenalan Lun Bawang. Diperoleh pada $9 \quad$ September 2019 daripada: http://mypmbudayaetnik.blogspot.com/2018/01/pengenalan-lun-bawang-membawa maksud.html

Suku Kaum Lun Bawang. Diperoleh pada 11 Oktober 2019 daripada: http://limbangku.blogspot.com/2011/01/history-info-bout-my-suku-kaum-lun.html

Sejarah Sarawak. Diperoleh pada 8 September 2019 daripada: https://mohdharmanmdrodzi.wordpress.com/matapelajaran-kajian-tempatan/topik-2-sejarah-sarawak/ 